\title{
Implementasi Asymmetric Encryption RSA Pada Port Knocking Ubuntu Server Menggunakan Knockd Dan Python
}

\author{
Mukhammad Zainal Amir Mahmud*1, Syaifuddin ${ }^{2}$, Diah Risqiwati ${ }^{3}$ \\ 1,2,3 Teknik Informatika/Universitas Muhammadiyah Malang \\ Zainal0909@gmail.com*1, saifuddin@umm.ac.id²,risqiwati@umm.ac.id ${ }^{3}$
}

\begin{abstract}
Abstrak
Penelitian dalam mekanisme otentikasi telah mengarah pada rancangan dan pengembangan skema baru. Keamanan yang disediakan oleh metode ini harus ditinjau dan dianalisis sebelum dapat digunakan secara luas. Dalam penelitian ini, kami menganalisis beberapa kelemahan dari metode autententikasi port knocking yang membuatnya rentan terhadap banyak serangan. Kami akan menyajikan serangan Sniffing, di mana penggunaan yang tidak sah dapat memperoleh akses ke server yang dilindungi hanya dengan melakukan perekaman lalu lintas data yang ada pada jaringan lokal menggunakan tools wireshark. Untuk itu metode port knocking akan dikembangkan, port knocking ini menggunakan knockd yang ada pada ubuntu server, port knocking merupakan metode melindungi port yang penting agar tidak dapat terlihat segai port yang terbuka. Namun metode port knocking ini masih memiliki kelemahan terhadap serangan seperti TCP replay, bruteforce, dan lain-lain. Penelitian ini mengusulkan metode autentikasi dan end to end connection untuk menambah keamanan pada metode port knocking. user harus melakukan koneksi end to end terlebih dahulu sebelum melakukan knocking, setelah melakukan knocking user juga harus melakukan autentikasi pada server untuk dapat membuka port yang diinginkan.
\end{abstract}

Kata Kunci: Knocking, Authentication, Knockd, End to End

Abstract

Research in authentication mechanisms has led to the design and development of a new scheme. Security provided by these methods must be reviewed and analyzed before it can be widely used. In this study, we analyze some of the weaknesses of the port knocking method autententikasi which makes it vulnerable to many attacks. We will present Sniffing attacks, where unauthorized use can obtain access to the protected server just by doing the recording of data traffic on the local network using wireshark's tools. For that port knocking method will be developed, port knocking uses knockd on ubuntu server, port knocking is a method of protecting an important port in order not to be seen as an open port. But the port knocking method still has a weakness against attacks such as TCP replay, bruteforce, and others. This research proposes a method of authentication and end to end connection to increase security at the port knocking method. the user must connect end to end first before doing the knocking, after knocking the user must also perform authentication on the server to be able to open the port that you want.

Keywords: Knocking, Authentication, Knockd, End to End

\section{Pendahuluan}

Autentikasi telah menjadi masalah dalam kemanan komunikasi dalam dekade terakhir, para pelaku melakukan identifikasi sebelum koneksi terjadi antara satu sama lain, sehingga pelaku dapat mendapatkan akses dengan menggunakan teknik teknik penyerangan tertentu. Seperti yang kita ketahui , "jalur akses" ke komunikasi, jadi target utama pelaku potensial untuk penyerang. Ini berarti proses autentifikasi harus diamankan dengan menggunakan protokol atau mekanisme yang memungkinkan masing-masing prinsip melakukan verifikasi identitas sebelum melakukan komunikasi, hal dasar dalam melakukan autentikasi adalah dengan memasukkan username dan password [1].

Port knocking merupakan mekanisme autentikasi pada server yang hanya diketahui oleh orang yang menggunakan metode ini [2]. Dalam hal ini, kata sandi bukanlah urutan karakter tetapi urutan port: Server membuat semua port jaringannya tertutup dan port ini harus "diketuk" dalam urutan yang benar agar server dapat membuka port komunikasi yang diinginkan. Prosedur untuk 
"mengetuk" port terdiri atas pengiriman paket ke port itu, sehingga server akan melihat upaya koneksi terhadap port tertutup dan mencatatnya [3].

Keuntungan menggunakan port knocking yaitu dapat menutup semua port pada jaringan tersebut, sehingga jika dilakukan scanning maka penyerang tidak menemukan port yang terbuka, klien harus melakukan ketukan dengan benar untuk membuka port yang tertutup dapat terbuka [4]. Port knocking adalah sebuah metode yang menutup service dari penyerang dengan cara data ditransmisikan melalui port yang tertentu. Pada dasarnya Port knocking merupakan sebuah mekanisme keamanan jaringan yang tertanam dalam Firewall pada Secure Computer System [5]. Pada referensi lain mengatakan bahwa Port knocking adalah sebuah metode otorisasi user berdasarkan firewall untuk melakukan komunikasi melalui port yang tertutup [2]. Serangan yang umum terjadi antara lain adalah DDoS dan NAT knocking, DDoS pada port knocking menyebabkan server terlalu sibuk memproses paket dari client yang melakukan serangan sehingga server menjadi sangat terbebani dan akhirnya layanan pada server tersebut menjadi terganggu, DDoS ini menekankan pada pengiriman paket SYN secara terus menerus dari client dengan pemalsuan IP Address dari client tersebut sehingga server akan sibuk mengirimkan paket SYN,ACK dan pada client yang menyerang server tersebut paket ACK yang seharusnya dikirim kembali ke server tidak dikirimkan sebagaimana mestinya [6]. NAT knocking adalah serangan yang memungkinkan client yang tidak valid dapat memiliki akses ke suatu sistem, konsep serangan ini adalah saat ada client yang berada dibalik NAT menggunakan port knocking untuk masuk ke suatu sistem maka si penyerang akan menunggu sampai client tersebut menyelesaikan sequence port knockingnya sampai port yang menjadi tujuan client tersebut terbuka, dari sini penyerang akan mencoba masuk ke port tersebut tanpa melakukan knocking karena client yang sebelumnya melakukan knocking telah membuka akses ke port, bila si penyerang dapat masuk ke port tersebut maka pada server yang menjalankan port knocking dipastikan tidak memvalidasi client yang terhubung dengannya [5].

Pada penelitian yang dilakukan oleh Leleh Boroumand yang berjudul "Virtualization Technique for Port knocking in Mobile Cloud Computing" memberikan saran agar timeout sequence yang digunakan memiliki banyak variasi dikarenakan celah ini memberikan kesempatan bagi seorang penyerang untuk menemukan sequence yang tepat [7]. Pada penelitian yang dilakukan oleh Mehran Pourvahab yang berjudul"Secure Port knockingTunneling" menyatakan bahwa pemanfaatan tunneling pada penelitiannya memberikan pengamanan dalam komunikasi dan mencegah NAT-knocking dan untuk pengembangannya kedepan diperlukan sequence dan model enkripsi yang lebih baik guna mengurangi kinerja berlebih pada server [8]. pada dasarnya metode port knocking ini masih rentang terhadap serangan sniffing, namun yang membedakan dari penelitian sebelumnya yaitu tingkat kesulitan untuk memecahkan payload yang didapat dari hasil sniffing [9].

Pada penelitian, ini peneliti akan mencoba mengimplementasikan autentikasi client port knocking pada ubuntu server versi 16. Authentication ini dilakukan client pada server yang bertujuan untuk memvalidasi client yang melakukan knocking ke server, guna menghindari serangan bruteforce. dan menambahkan end to end koneksi yang bertujuan meningkatkan keamanan port knocking. Dan menambahkan tunneling antara client dan server, sehingga lebih memungkinkan menambah untuk keamanan port knocking itu sendiri.

\section{Metode Penelitian}

Port knocking memungkinkan terjadinya komunikasi antar host melalui port yang tertutup secara umum terdapat berbagai metode yang bisa diterapakan dalam port knocking, informasi yang dikirmkan dapat berupa sequence ataupun payload yang berisi data, dalam prakteknya data yang dikirm dalam bentuk payload akan diterima oleh daemon yang bertugas menunggu dan mengobservasi sequence yang dikirm oleh client ataupun isi payload yang dikirm oleh client. Dalam port knocking, server yang bertindak sebagai penyedia layanan port knocking tidak membuka port yang akan digunakan untuk komunikasi, melainkan menyediakan listener terhadap paket SYN pada port tertentu sehingga ketika port yang diberi listener tersebut menerima paket SYN dari client dapat digunakan sebagai acuan suatu autentikasi berdasarkan sequnce. Sebagai contoh disediakan port $(1145,1087,1172)$ yang bertugas menerima SYN dari client, ketika client berhasil mengirim SYN ke port-port tersebut dalam interval waktu tertentu maka dapat diasumsikan client tersebut valid karena informasi knock sequence ini bersifat sangat rahasia dan hanya diketahui oleh admin dan client saja[10].

REPOSITOR, Vol. 2, No. 6, Juni 2020: 787-794 


\subsection{Skenario Program}

Tahapan ini merupakan perancangan sistem terhadap solusi dari permasalahan yang ada dengan menggunakan perangkat pemodelan sistem seperti alur sistem dan flowchart, pada alur akan digambarkan runtutan kinerja program pada penelitian ini, pada bagian flowchart akan menggambarkan alur program yang jalankan seperti pada Gambar 1.

4. admin melakukan authentication

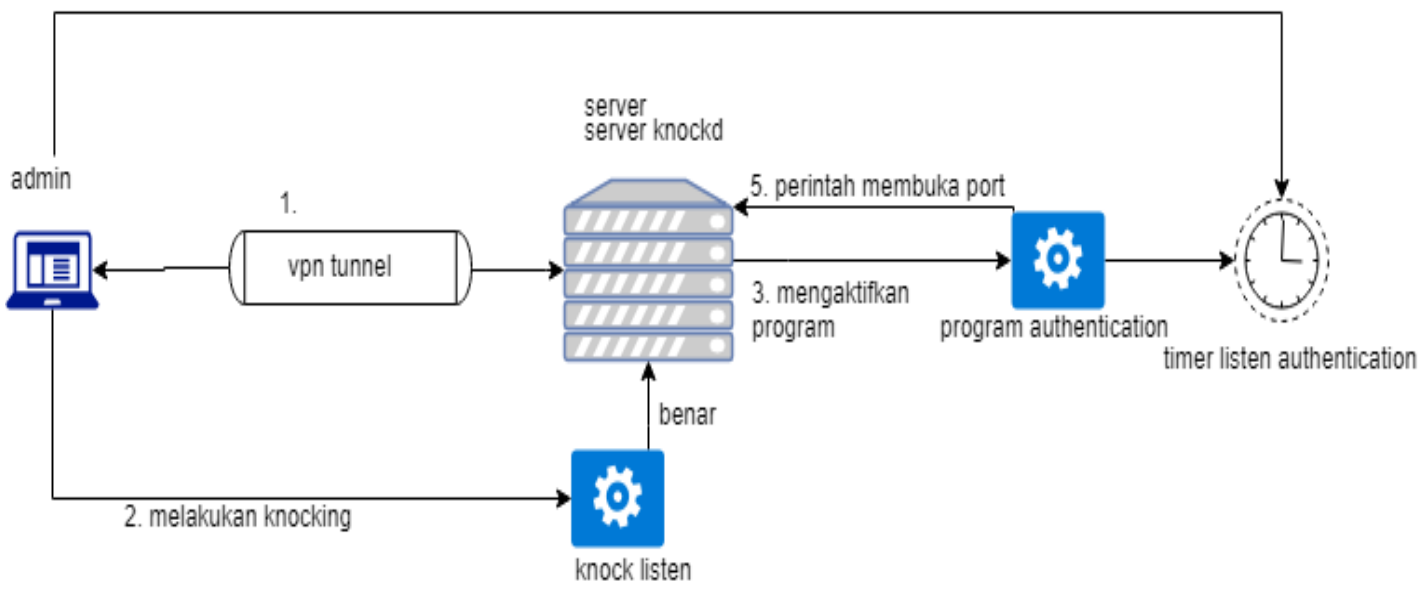

Gambar 1. Alur Sistem

Pada Gambar 1 merupakan gambaran dari urutan yang harus dilalui oleh client dalam melakukan port knocking autentikasi.

1. Nomor 1 admin diharuskan melakukan tunnel ke server.

2. admin melakukan knocking dengan menginsialisasi port yang telah ditentutakan contoh 100020003000.

3. Secara otamatis server mengaktikan program autentikasi, jika tidak ada yang melakukan autetikasi selama waktu yang telah ditentukan program akan dinonaktifkan. Untuk membuka harus melakakuan nomor 2 terlebih dahulu.

4. admin melakukan autentikasi dengan mengaktifkan program yang hanya ada pada admin valid. Jika autentikasi melewati batas waktu maka akan diulang ke nomor 2.

5. Program akan mengirimkan perintah untuk membuka port yang telah di tutup.

Penggunaan algoritma RSA dalam pembuatan public dan private key digunakan dengan tujuan untuk mengamankan payload yang dikirmkan menggunakan komunikasi socket menggunakan bahasa pemrograman python, payload tersebut harus dienkripsi terlebih dahulu oleh firewall yang menjalankan daemon knockd kemudian bila ada client yang melakukan knocking maka payload tersebut akan dikirim ke client kemudian tugas client adalah mendekrip payload tersebut untuk dikirim kembali ke firewall sebagai autentikasi dan validasi, proses enkripsi dari firewall ke client akan menggunakan kunci public yang dimiliki oleh firewall sementara pada client akan menggunakan kunci private untuk membuka payload tersebut.

Penggunaan tunneling digunakan untuk menambah keamanan pada autentikasi, admin harus melakukan tunneling sebelum melakukan knocking dan autentikasi. program autentikasi akan berjalan jika admin dan server terhubung dengan VPN, jika tidak admin tidak bisa melakukan autentikasi. Admin tidak dapat membuka port yang diinginkan walaupun sudah melakukan knocking, dikarenakan program autentikasi menggunakan IP address VPN untuk melakukan autentikasi.

Penggunaan timeout untuk mebatasi program melakukan waiting autentikasi, sehingga server tidak akan menunggu lama untuk balasan autentikasi dari admin. Jika program melewati batas waktu yang ditentukan, maka program akan dimatikan atau dihentikan. Sehingga server akan melakukan listen port kembali, jika ada permintaan dengan mengetuk port tertentu, maka program akan bisa digunakan kembali.

Perancangan alur sistem ini dapat menambah keamanan pada metode port knocking, sehingga metode ini akan membantu mengamankan port yang sering terjadi eksploitasi. Penamabahan keamanan tunneling dan autentikasi hampir tidak mungkin untuk dapat mengksploitasi pada port yang dilindungi oleh metode ini. 


\subsection{Perancangan Sistem VPN}

Pada perancangan sistem VPN akan dijelaskan pada Gambar 2.

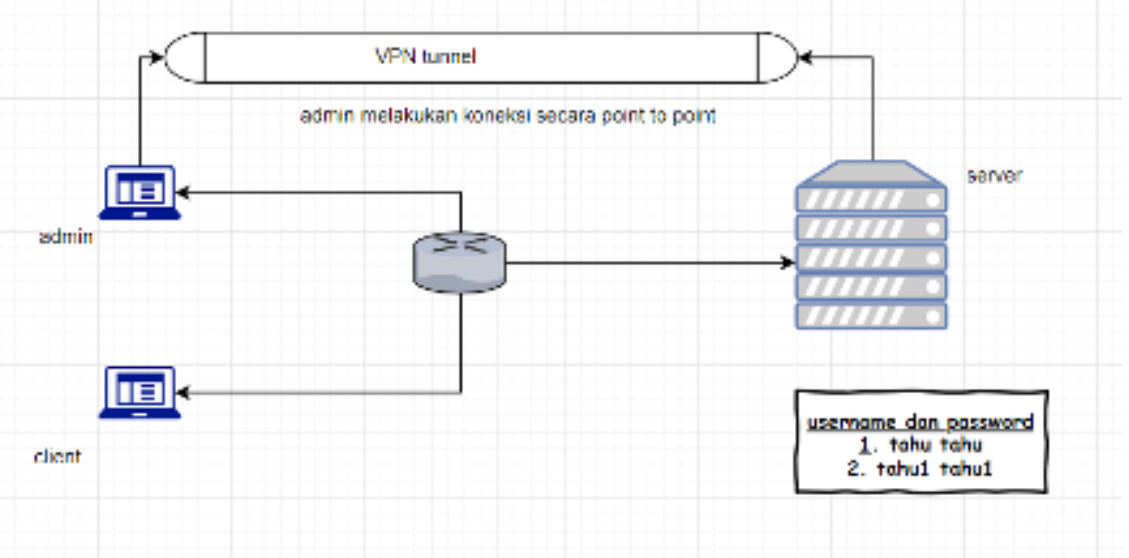

Gambar 2. Alur Tunnel VPN

Pada Gambar 2 dijelaskan admin berada satu network dengan client, untuk masuk jaringan private admin harus mengetahui username dan password.

1. Server mengaktifkan layanan ptpp.

2. Admin mengaskes VPN menggunakan username dan password.

3. Admin dapat masuk pada jaringan private.

Perancangan VPN tunnel ini menggunakan PPTPD pada server. Server menggunakan ubuntu server, PPTPD merupakan sebuah fitur pada server untuk digunakan sebagai VPN server. Admin menggunakan username dan password untuk dapat melakukan koneksi private terhadap server ataupun dengan client yang lain. VPN dapat menambah keamanan pada metode port knocking .

\subsection{Tahapan Sistem}

Metode port knocking pada penelitian ini memiliki 3 tahapan yang digunakan untuk melakukan otorasi client, client harus melewati tahapan untuk membuka port yang tertutup tersebut, yang pertama client melakukan tunneling ke server sehingga didalam satu jaringan private, kedua melakukan ketukan yang telah ditentukan, dan yang terakhir melakukan autentifikasi pada server.

Proses pertama adalah melakukan koneksi tunnel antara client dan server sehingga berada dalam satu jaringan private, untuk melakukan jaringan private user harus menggunakan username dan password yang sudah ditentukan pada server. Username dan password dibuat pada saat konfigurasi VPN pada server, hanya username dan password yang terdaftar yang bisa login VPN.

Proses kedua adalah melakukan ketukan untuk menjalankan sebuah program autentifikasi yang otomatis berjalan setelah melakukan ketukan dengan benar. Tahapan ini merupakan awal untuk membuka port yang diinginkan pada metode port knocking.

Proses ketiga adalah autentifikasi dari client, client harus dapat mengautentikasikan diri sehingga proses dapat berlanjut, setelah client dapat mengautentikasikan dirinya, client dapat menggunakan layanan yang dibutuhkan, proses ini digunakan untuk mencegah serangan replay attack dan bruteforce. Untuk authentication ini menggunakan program yang diletakan di server dan client, client harus mengaktifkan program sehingga dapat melakukan authentication pada server, sebaliknya pada server program automatic ketika knocking yang dilakukan client berhasil.

\section{Hasil Dan Pembahasan}

Pengujian dilakukan dengan sistem pada penelitian ini menggunakan serangan sniffing dan bruteforce. Pada pengujian ini akan dialakukan tiga sistem uji yaitu port knocking biasa, port knocking ditambahkan dengan autentikasi program, serta port knocking ditambahkan autentikasi dan VPN. Dari percobaan serangan pada tiga sistem dapat diketahui perbedaan dari tiga sistem tersebut.

REPOSITOR, Vol. 2, No. 6, Juni 2020: 787-794 


\subsection{Port knocking Biasa}

Langkah-langkah yang digunakan pada port kncoking biasa agar dapat membuka port.

1. Server melakaukaan listening port.

2. Admin melakukan knocking pada server knockd.

3. Menerima Ketukan dengan benar dari admin.

4. Server membuka akses port yang dilindungi

Tabel 1. Hasil Port Knocking Biasa

\begin{tabular}{cc}
\hline Serangan & Port Dapat Terbuka \\
\hline Bruteforce & ya \\
Sniffing & ya \\
\hline
\end{tabular}

Kesimpulan yang didapat dari Tabel 1 adalah serangan bruteforce dapat membuka port yang tertutup dengan cara melakukan ketukan secara urut sampai menemukan kombinasi kunci yang telah ditentukan oleh admin. Dan serangan sniffing juga dapat menemukan kombinasi kunci dengan melakukan perekaman lalu lintas data yang ada pada jaringan lokal, kombinasi kunci akan diketahui jika admin melakukan knocking dan terekam oleh wireshark. Sehingga penyerang dapat menggunakan kunci untuk memperoleh akses port yang tertutup.

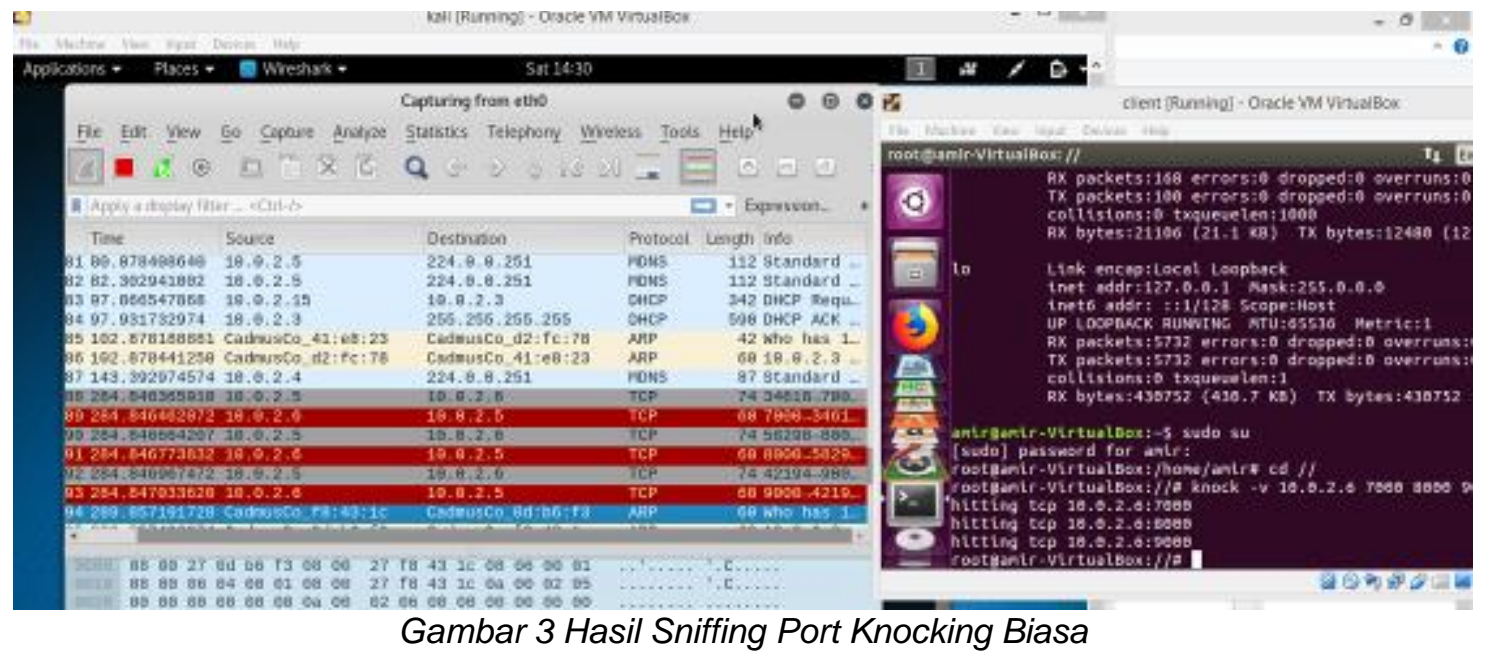

Pada Gambar 3 dapat disimpulkan aktifitas client ke server terkam oleh wireshark, dan penyerang mendapatkan kombinasi kunci yang benar.

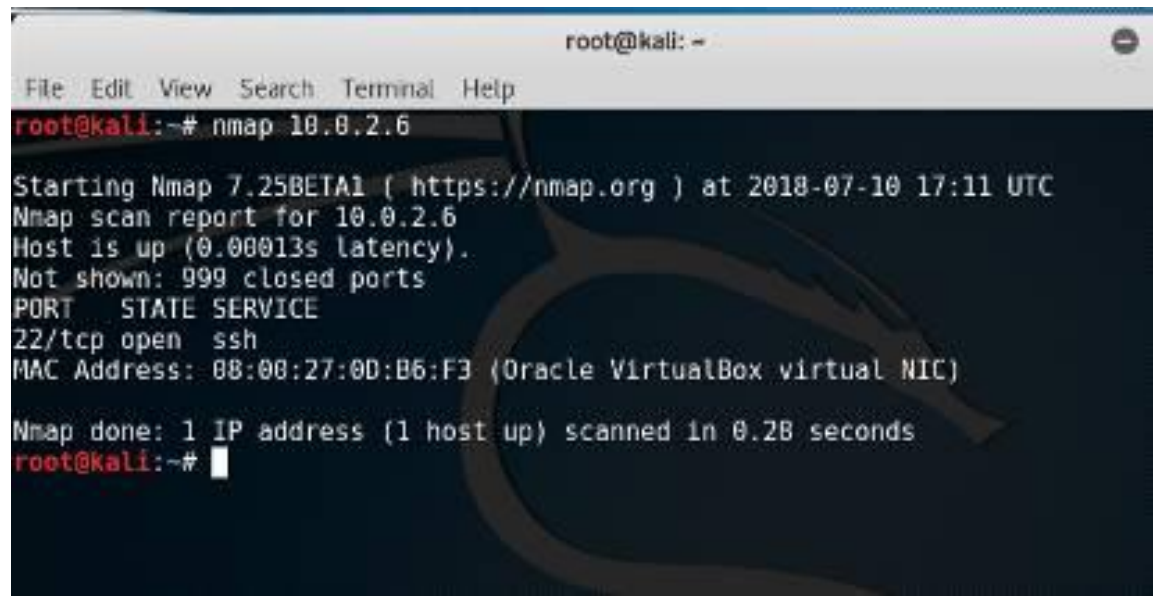

Gambar 4. Hasil Bruteforce

Pada Gambar 4 dijelaskan port akan terbuka jika serangan bruteforce berhasil menemukan kombinasi kunci yang benar. 


\subsection{Port knocking Autentikasi}

Langkah-langkah yang digunakan pada port kncoking biasa agar dapat membuka port.

1. Server melakaukaan listening port.

2. Admin melakukan knocking pada server knockd.

3. Menerima Ketukan dengan benar dari admin.

4. Server menjalankan program autentikasi.

5. Admin melakukan autentikasi.

6. Server membuka akses port yang dilindungi

Tabel 2. Hasil Port knocking Autentikasi

\begin{tabular}{cc}
\hline Serangan & Port Dapat Terbuka \\
\hline Bruteforce & tidak \\
Sniffing & tidak \\
\hline
\end{tabular}

Kesimpulan yang didapat dari Tabel 2 adalah serangan bruteforce tidak dapat membuka port yang tertutup, walaupun menemukan kombinasi kunci yang telah ditentukan oleh admin dikarenakan adanya step autentikasi yang harus dilakukan setelah knocking. Dan serangan sniffing juga dapat menemukan kombinasi kunci namun juga tidak dapat mengakses dikarenakan harus melakukan autentikasi terlebih dahulu untuk membuka port yang tertutup tersebut.

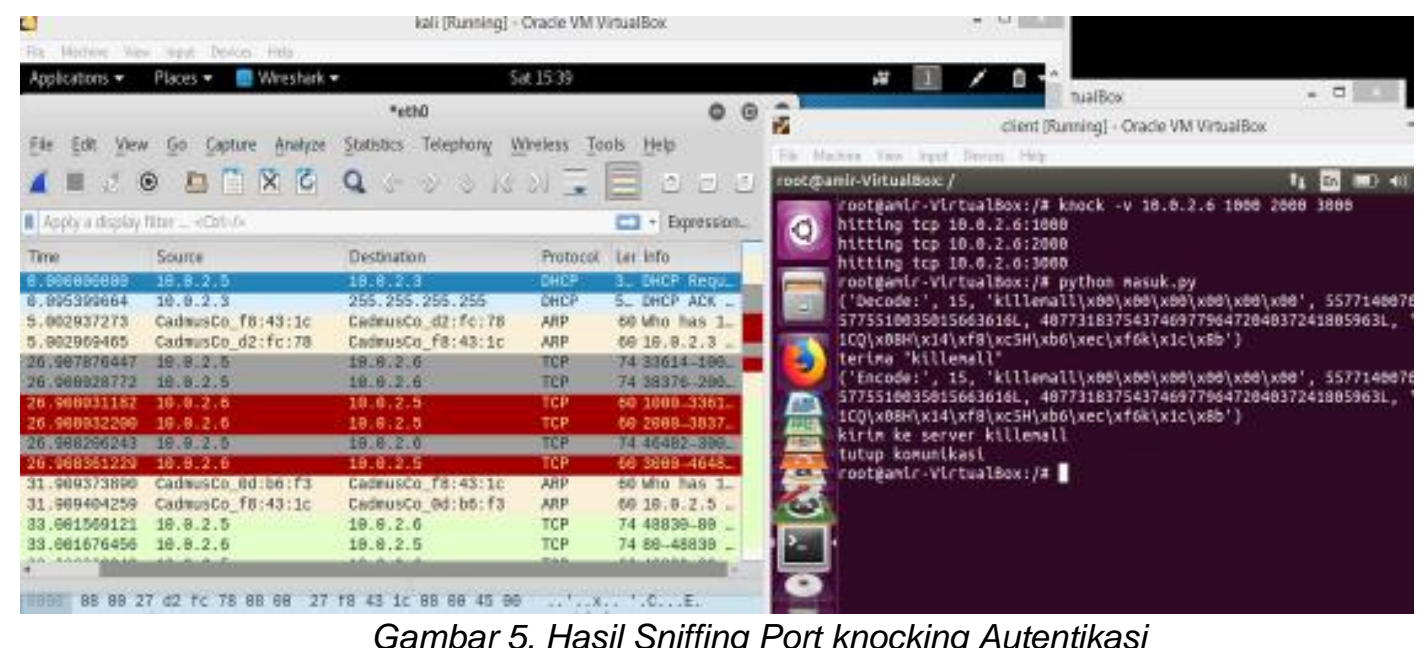

Pada Gambar 5 dapat dijelaskan serangan sniffing juga dapat menemukan kombinasi kunci, Namun tidak dapat mengakses layanan diakrenakan adanya proses autentikasi setelah proses knocking.

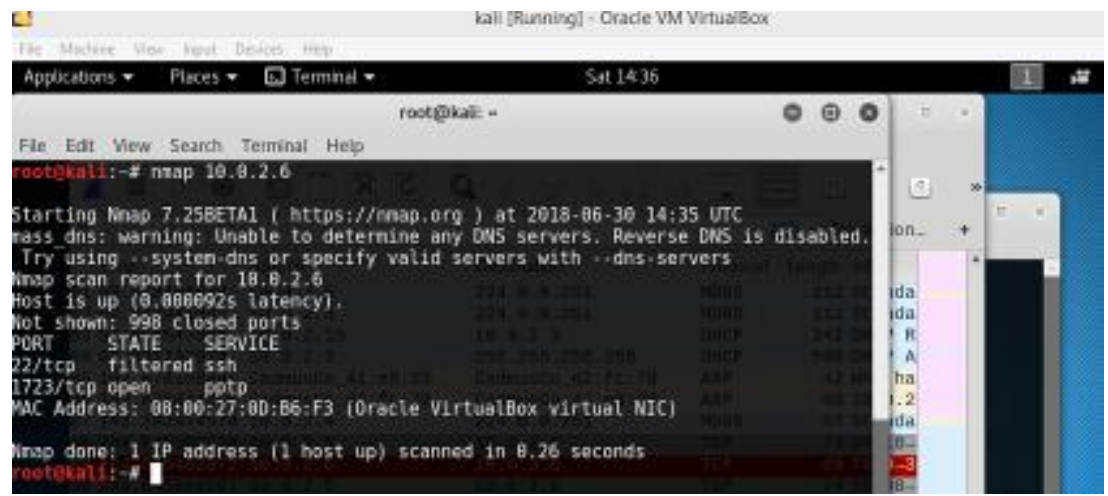

Gambar 6. Hasil Bruteforce Port knocking Autentikasi

Pada Gambar 6 dapat dijelaskan penyerangan tidak dapat mengetahui adanya autentikasi setelah knocking, sehingga penyerang tidak dapat mengakses layanan dikarenakan status port masih filtered.

REPOSITOR, Vol. 2, No. 6, Juni 2020: 787-794 


\subsection{Port Knoking Autentikasi VPN}

Langkah-langkah yang digunakan pada port kncoking biasa agar dapat membuka port.

1. Server membuka layanan pptp

2. Admin melakukan jaringan private

3. Server melakaukaan listening port.

4. Admin melakukan knocking pada server knockd.

5. Menerima Ketukan dengan benar dari admin.

6. Server menjalankan program autentikasi.

7. Admin melakukan autentikasi.

8. Server membuka akses port yang dilindungi

Table 3. Hasil Port knocking Autentikasi VPN

\begin{tabular}{cc}
\hline Serangan & Port Dapat Terbuka \\
\hline Bruteforce & tidak \\
Sniffing & tidak \\
\hline
\end{tabular}

Kesimpulan yang didapat dari Tabel 3 adalah serangan bruteforce tidak dapat membuka port yang tertutup, walaupun menemukan kombinasi kunci yang telah ditentukan oleh admin dikarenakan adanya step autentikasi yang harus dilakukan setelah knocking dan adanya juga proses tunnel terlebih dahulu sebelum melakukan knocking. Dan serangan sniffing juga dapat menemukan kombinasi kunci namun juga tidak dapat mengakses dikarenakan harus melakukan autentikasi terlebih dahulu untuk membuka port yang tertutup tersebut dan adanya juga proses tunnel terlebih dahulu sebelum melakukan knocking. Autentikasi pada sistem ini juga menggunakan IP address setelah tunnel. jika admin ingin melakukan melakukan autentikasi harus terlebih dahulu masuk dalam jaringan private.

\subsection{Analisa Pengujian Sistem}

Setelah melakukan pengujian pada tiga sistem diatas terdapat perbedaan hasil dari pengujian tersebut. Perbedaan yang paling terlihat dari tiga sistem yaitu hasil sistem port knocking biasa, hasil dari pengujian sistem 2 dan yang ketiga terlihat tidak jauh berbeda, seperti pada Tabel 4.

Tabel 4. Hasil Analisa Pengujian Tiga Sistem

\begin{tabular}{cccc}
\hline \multirow{2}{*}{ Sistem } & \multicolumn{2}{c}{ Percobaan serangan } & \multirow{2}{*}{ Dapat masuk SSH } \\
\cline { 2 - 3 } & Sniffing & Bruteforce & \\
Sistem 1 & Ya & Ya & Ya \\
Sistem 2 & Ya & Tidak & Tidak \\
Sistem 3 & Ya & Tidak & Tidak \\
\hline
\end{tabular}

Setelah melakukan serangan sniffing dan bruteforce dapat dengan media server yang menggunakan knockd standard, knockd +autentikasi dan knockd +autentikasi+VPN. Pada knockd standard dilakukan sniffing dan mendapatkan sequence yang digunakan untuk mengakses port knocking pada server, pada saat client melakukan knocking ke server. Jika penyerang menggunakan tersebut maka akan dapat mengakses SSH pada server tersebut. Namun pada server knockd + autentikasi, jika dilakukan sniffing juga akan mendapatkan sequence untuk mengakses SSH, Namun penyerang tidak dapat akses SSH dikarenakan setelah knocking harus melakukan autentikasi yang dimiliki oleh client yang sah. Dan sistem yang menggunakan knockd +autentikasi+VPN, Hanya dapat merekam kombinasi kunci namun tidak dapat merakam autentikasinya.

Percobaan kedua yaitu melakukan serangan buteforce, pada server knockd standard serangan buterforce dapat menemukan kombinasi sequence namun membutuhkan waktu dan serangan dapat melakukan akses SSH setelah menemukan kombinasi sequence dengan cara mengetuk secara looping. Pada server knockd + autentikasi dicoba juga di serang menggunakan bruteforce namun setelah menemukan kombinasi sequence dengan cara melooping port, penyerang juga tidak dapat mengakses SSH dikarenakan harus melakukan autentikasi terlebih dahulu. Tidak jauh beda pada server knockd + autentikasi+VPN dilakukan serangan menggunakan bruteforce namun setelah menemukan kombinasi sequence dengan cara 
melooping port, penyerang juga tidak dapat mengakses SSH dikarenakan harus melakukan autentikasi terlebih dahulu.

\section{Kesimpulan}

Port knocking memiliki potensi pengembangan yang cukup baik terutama dibagian pengamanan sequence dan timeout serta autentikasi yang terjadi setelah melakukan knocking, dalam penelitian ini metode asymmetric enctyption RSA digunakan guna autentikasi dari server ke client dan sebaliknya, tidak hanya itu proses enkrip dan dekrip dilakukan dengan waktu yang paling cepat, sehingga proses knocking tidak membutuhkan waktu yang lama. Berdasarkan penelitian tentang metode port knocking yang telah dilakukan oleh peneliti. Berdasarkan hasil uji sistem port knocking yang dilakukan oleh peneliti, maka dapat menyimpulkan saran kepada peneliti selanjutnya, yaitu memperbaiki bug yang ada pada sistem knockd itu sendiri, knockd tidak mampu mengontrol jika user melakukan knocking lebih dari satu kali , knockd akan menuliskan rule setiap knocking user benar. Untuk penelitian selanjutnya agar dapat memperbaiki bug yang terjadi pada knockd itu sendiri.

\section{Referensi}

[1] S. Ibbi, "Memberikan Akses Legal Terhadap Port Tertentu Yang Telah Ditutup oleh Firewall dengan Metode Port Knocking," pp. 1-9.

[2] M. Rash, linux Firewalls: Attack Detection and Response with iptables, psad, and fwsnort. No Starch Press, 2007.

[3] A. I. Manzanares, J. T. Márquez, J. M. Estevez-Tapiador, and J. C. H. Castro, "Attacks on port knocking authentication mechanism," Lect. Notes Comput. Sci., vol. 3483, no. April, pp. 1292-1300, 2005.

[4] dkk M. Fahru Rozi, "Implementasi Remote Server Menggunakan Metode Port Knocking dengan Asymetric Encryption," Semin. TA, vol. 2, no. Jaringan Komputer, pp. 1-5, 2010.

[5] Z. A. Khan, N. Javaid, M. H. Arshad, A. Bibi, and B. Qasim, "Performance evaluation of widely used portknoking algorithms," Proc. 14th IEEE Int. Conf. High Perform. Comput. Commun. HPCC-2012 - 9th IEEE Int. Conf. Embed. Softw. Syst. ICESS-2012, pp. 903-907, 2012.

[6] D. Isabel, "InfoSec Reading Room Port Knocking: Beyond the Basics Port Knocking: Beyond the Basics In tu ho f rig," Inf. Secur.

[7] L. Boroumand, M. Shiraz, A. Gani, and R. Khokhar, "Virtualization Technique for Port Knocking in Mobile Cloud Computing," vol. 6, no. 1, pp. 1-25, 2014.

[8] P. Mehran, E. A. Reza, and B. Laleh, "SPKT: Secure Port Knock-Tunneling, an enhanced port security authentication mechanism," 2012 IEEE Symp. Comput. Informatics, Isc. 2012, no. March 2015, pp. 145-149, 2012.

[9] C. Indore, "A Result Analysis of Modified Hybrid Port Knocking ( MHPK) With Strong Authentication," vol. 14, no. 3, pp. 107-114, 2014.

[10] M. Krzywinski, "Port knocking from the inside out," SysAdmin Mag., vol. 12, no. 6, pp. $12-$ 17, 2003. 